\title{
Het bepalen van het optimale tijdstip voor keizersnede bij de hond in functie van de voorspelde partusdatum
}

\author{
${ }^{1}$ T. Goessens, ${ }^{2}$ B. Van Goethem, ${ }^{2}$ H. de Rooster, ${ }^{3}$ E. Van Der Vekens, ${ }^{2}$ I. Polis, \\ ${ }^{1}$ A. Van Soom, ${ }^{1}$ E. Wydooghe
}

${ }^{1}$ Vakgroep Voortplanting, Verloskunde, en Bedrijfsdiergeneeskunde, Faculteit Diergeneeskunde, UGent, Salisburylaan 133, B-9820 Merelbeke

${ }^{2}$ Vakgroep Kleine Huisdieren, Faculteit Diergeneeskunde, UGent, Salisburylaan 133, B-9820 Merelbeke

${ }^{3}$ Vakgroep Medische Beeldvorming van de Huisdieren, Faculteit Diergeneeskunde, UGent,

Salisburylaan 133, B-9820 Merelbeke

Eline.Wydooghe@Ugent.be

\section{AMENVATTING}

Het optimale tijdstip bepalen voor de keizersnede bij de hond kan een uitdaging betekenen voor de praktijkdierenarts. Er moet rekening gehouden worden met de berekende partusdatum, het al dan niet op gang zijn van de partus en het al dan niet aanwezig zijn van dystocie. Sommige teven hebben een verlengde dracht, bij andere start de partus te vroeg. In beide gevallen is de kans op overleving van de pups zeer laag. Ook wanneer er bij dystocie te lang gewacht wordt om een keizersnede uit te voeren, komt de overleving van de pups in het gedrang. Het is daarom van groot belang de juiste partusdatum bij elke individuele hond te kunnen voorspellen, zeker bij risicopatiënten. De partusdatum kan berekend worden door het begin van de metoestrus te bepalen via vaginale cytologie of door embryonale en foetale structuren te meten via echografie. De meest accurate methode is echter door middel van cyclusopvolging met progesteronmeting.

\section{INLEIDING}

Elke (hobby)hondenfokker hoopt op een vlotte bevalling van zijn teven en een goede overleving van de pups. Het is daarom belangrijk om de partusdatum zo accuraat mogelijk te voorspellen, zodat er op dat moment (diergeneeskundige) hulp kan voorzien worden. Opdat een keizersnede niet te vroeg of te laat uitgevoerd wordt, is het daarnaast belangrijk te weten of een teef effectief op de uitgerekende datum aangeboden wordt in het geval een verlengde dracht of wanneer dystocie vermoed wordt. Wanneer een keizersnede te vroeg wordt uitgevoerd, kunnen de pups nog immatuur of niet levensvatbaar zijn. Wanneer er echter te lang wordt gewacht, kan de placenta niet meer in de behoefte van de pups voorzien en sterven de pups in utero (Lopate, 2012). Er werd bovendien aangetoond dat de kans dat alle pups na een spoedkeizersnede levend geboren worden slechts $30 \%$ bedraagt van de kans op overlevende pups bij een geplande ingreep (Moon et al., 2000). Daarom is het zeer belangrijk om teven die een verhoogd risico hebben op dystocie op voorhand te identificeren en een correcte voorspelling te doen van de partusdatum. Bijkomend is het aangewezen om de eigenaars goed te informeren over tekenen die kunnen wijzen op dystocie, zodat een keizersnede tijdig kan uitgevoerd worden met maximale overleving van de pups.
De partusdatum van de hond berekenen aan de hand van de datum van de eerste dekking is een techniek die in de praktijk vaak werd toegepast maar tegenwoordig niet meer wordt aangeraden. Vroeger werd als vuistregel aangegeven dat er kon gewacht worden met de keizersnede tot 67 dagen na de eerste dekking wanneer er één of twee pups verwacht werden; zelfs tot 71 dagen wanneer er meer pups waren (Gavrilovic et al., 2008; de Kruif, 2012). Dit is een vuistregel die tegenwoordig niet meer wordt gevolgd. Een belangrijke evolutie bij het bewust fokken van honden is namelijk het feit dat de teef tijdens de loopsheid niet meer vrij gedekt wordt door de reu, maar dat het vaak om begeleide dekkingen gaat na progesteroncontrole. Dit impliceert dat de teef typisch één tot drie dagen na de ovulatie voor de eerste keer wordt gedekt of geïnsemineerd, terwijl vroeger de eerste dekking plaatsvond zodra de teef dit toeliet. Het receptieve gedrag van de teef ontstaat door een verandering in de progesteron- en oestrogeenverhouding (dalende oestrogeengehaltes ten opzichte van stijgende progesteronwaarden) die typisch optreedt tijdens de oestrus. Echter, in de praktijk kunnen onderdanige teven de dekking ook buiten de oestrusfase toelaten, terwijl dominante teven de dekking altijd kunnen weigeren. Zo ook zullen sommige teven de dekking toelaten ruim voor de ovulatie, terwijl andere de dekking pas toelaten na de ovulatie (Lopate, 2012). Bij de ovulatie 


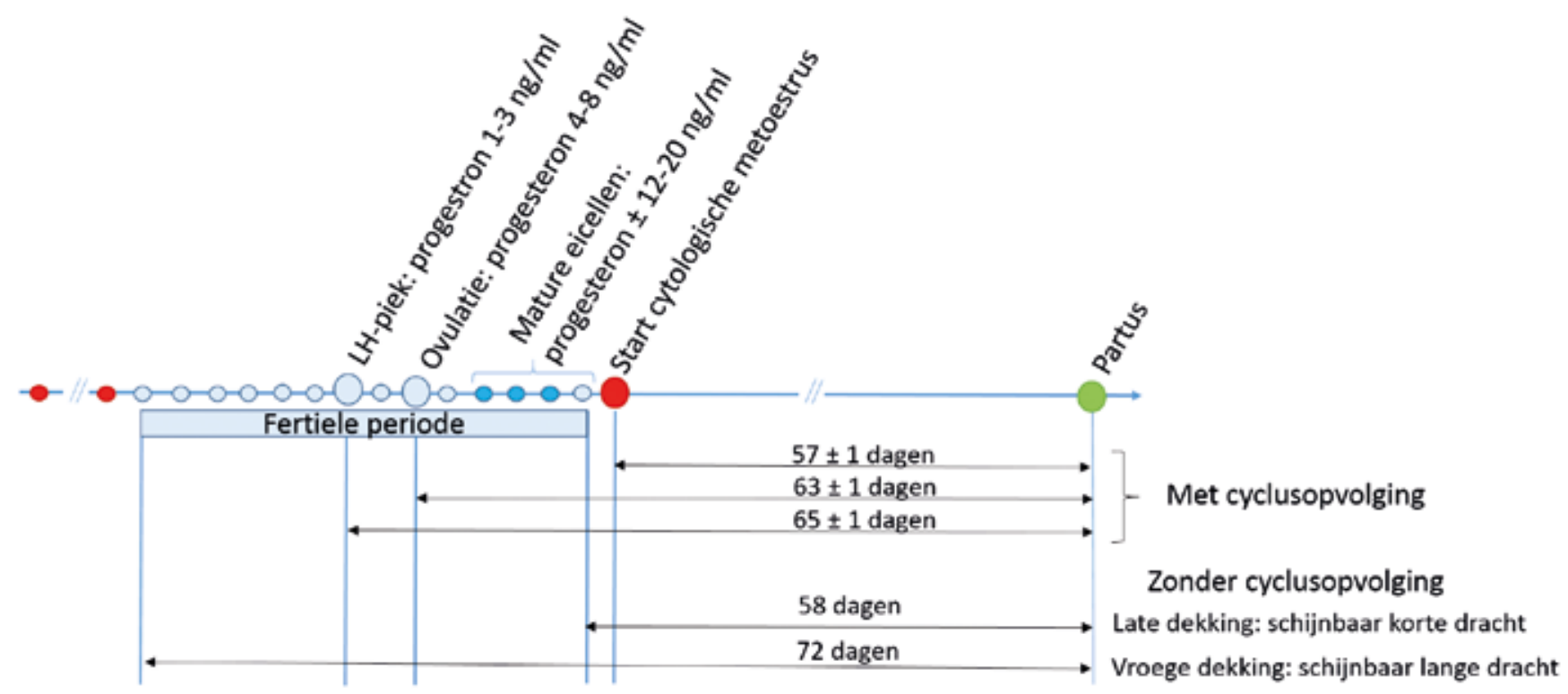

- Dag waarop dekking niet tot dracht zal leiden

- Dag waarop dekking tot een dracht kan leiden

- Dag waarop de kans het grootst is dat de dekking tot een dracht zal leiden

Figuur 1. Schematische weergave van de drachtduur bij de teef.

van de teef komen onrijpe eicellen vrij. Deze primaire oöcyten moeten 48 tot 72 uur rijpen vooraleer fertilisatie kan optreden. Het optimale moment voor een dekking is het moment dat er rijpe eicellen aanwezig zijn, i.e. twee tot vijf dagen na de ovulatie (Johnston et al., 2001b). Sperma van honden kan zeven tot tien dagen overleven in de baarmoeder. Dit impliceert dat de fertiele periode van een teef, de periode waarin een dekking tot bevruchting kan leiden, van acht dagen vóór de ovulatie tot vijf dagen na de ovulatie loopt (Figuur 1). Wanneer het moment van ovulatie niet wordt bepaald, is er bijgevolg een grote spreiding in de drachtduur en kan de partus plaatsvinden op eender welk moment tussen 58 en 72 dagen na de dekking (Davidson, 2010). Zo resulteert een dekking enkele dagen vóór de ovulatie in een schijnbaar lange dracht terwijl een dekking enkele dagen na de ovulatie resulteert in een schijnbaar korte dracht.

In dit overzicht wordt aangegeven hoe risicopatienten kunnen herkend en opgevolgd worden. Daarna wordt een aantal betrouwbare methoden beschreven om de partusdatum te voorspellen. Daarbij worden de verschillende technieken besproken die kunnen worden aangewend tijdens de cyclusopvolging, tijdens de dracht en bij een nakende partus. Tot slot wordt een aantal beslissingsregels opgesteld wanneer een keizersnede moet uitgevoerd worden bij risicopatiënten en bij teven die aangeboden worden met het vermoeden van verlengde dracht of van dystocie.

\section{IDENTIFICEREN EN OPVOLGEN VAN RISICO- PATIËNTEN}

Het bepalen van de juiste partusdatum is erg belangrijk wanneer men vermoedt dat er dystocie zou kunnen optreden bij een bepaalde teef. Risicofactoren voor dystocie bij de teef zijn: primipariteit en een leeftijd ouder dan vier jaar (tweemaal hoger risico), teven van grote rassen (>51 kg: tweemaal hoger risico; > $71 \mathrm{~kg}$ : driemaal hoger risico), en teven waarvan een erg klein (één of twee pups) of een erg groot nest (meer dan 10 pups) verwacht wordt (Bergstrom et al., 2006; Linde-Forsberg, 2005; Smith, 2007). Ook teven die behoren tot een risicoras, de brachycefalen en bepaalde terriërs, zoals de Boston terriër en de Schotse terriër, hebben een hoog dystocierisico, omdat de kop- en borstomtrek van de pup en de diameter van het bekken van de teef ongunstig zijn voor een vlotte partus (Eneroth et al., 1999; Bergstrom et al., 2006).

Een risicopatiënt (i.e. een patiënt met vermoeden van een groot of klein nest en met een afwijkend bekken) moet al tijdens de dracht goed opgevolgd worden. Met behulp van radiografie kan het aantal pups geschat worden vanaf 45 dagen dracht, omdat de foetale skeletten dan voldoende gemineraliseerd zijn (Lopate, 2012). Laterale en ventrodorsale radiografische opnamen van het bekken kunnen tevens genomen worden om het risico op dystocie in te schatten. De afplatting van het bekken kan worden weergegeven door de verhouding van de hoogte van het bekken (c) op de breedte van het bekkenkanaal ter hoogte van de iliumvleugels (s) en ter hoogte van het os pubis (Figuur 2A en 2B). Zo wijzen een c/s-verhouding kleiner dan 1,04 $\pm 0,02$ en een c/u-verhouding kleiner dan $0,61 \pm 0,02$ op een dorsoventrale afplatting en predisponeren voor dystocie (Eneroth et al., 1999). Bij dergelijke honden wordt vaak een keizersnede uitgevoerd hetzij electief of gepland, hetzij zodra men vermoedt dat er problemen kunnen optreden tijdens de ontsluiting of de uitdrijving. 


\section{HET VOORSPELLEN VAN HET PARTUSTIJD- STIP}

\section{Tijdens de cyclusopvolging}

Wanneer een hond aangeboden wordt voor cyclusopvolging, wordt naast een uitgebreide anamnese en inspectie van uiterlijke kenmerken, gebruik gemaakt van vaginale cytologie en progesteronbepaling om het correcte stadium van de cyclus in te schatten. Naast het bepalen van het ideale moment voor de dekking of kunstmatige inseminatie (KI) kan zowel vaginale cytologie als progesteronbepaling ook gebruikt worden om het tijdstip van de partus te bepalen. Hoewel deze gegevens beschikbaar zijn nog vóór men weet of de teef effectief drachtig is, zijn dit de meest correcte gegevens om de partusdatum te berekenen.

\section{Vaginale cytologie}

Bij de hond kan de partusdatum worden berekend door de start van de cytologische metoestrus te bepalen. Hiervoor wordt er vanaf het moment van de dekking dagelijks een vaginaal uitstrijkje genomen tot er een duidelijke overgang is van oestrus naar metoestrus (dag 1 van de metoestrus). In deze periode is er een overgang van verhoornde cellen, zoals superficiele en anucleaire cellen (het typische schollenbeeld), naar niet-verhoornde cellen, zoals parabasale en intermediaire cellen, en zijn er ook veel neutrofielen zichtbaar (Beccaglia et al., 2016) (Figuur 3A en 3B). De partusdatum kan prospectief worden berekend, want deze treedt op $57 \pm 1$ dagen na de start van de metoestrus. Recent werd aangetoond dat de accuraatheid van deze methode om de partusdatum $\pm 1 \mathrm{dag}, \pm 2$ dagen en \pm 3 dagen te voorspellen, overeenkomt met respectievelijk 88\%, 99\% en 100\% (De Cramer en Nothling, 2017). Een bijkomend voordeel van deze methode is dat ook retrospectief kan worden nagegaan of de dekkingen ongeveer op het goede moment plaatsvonden,
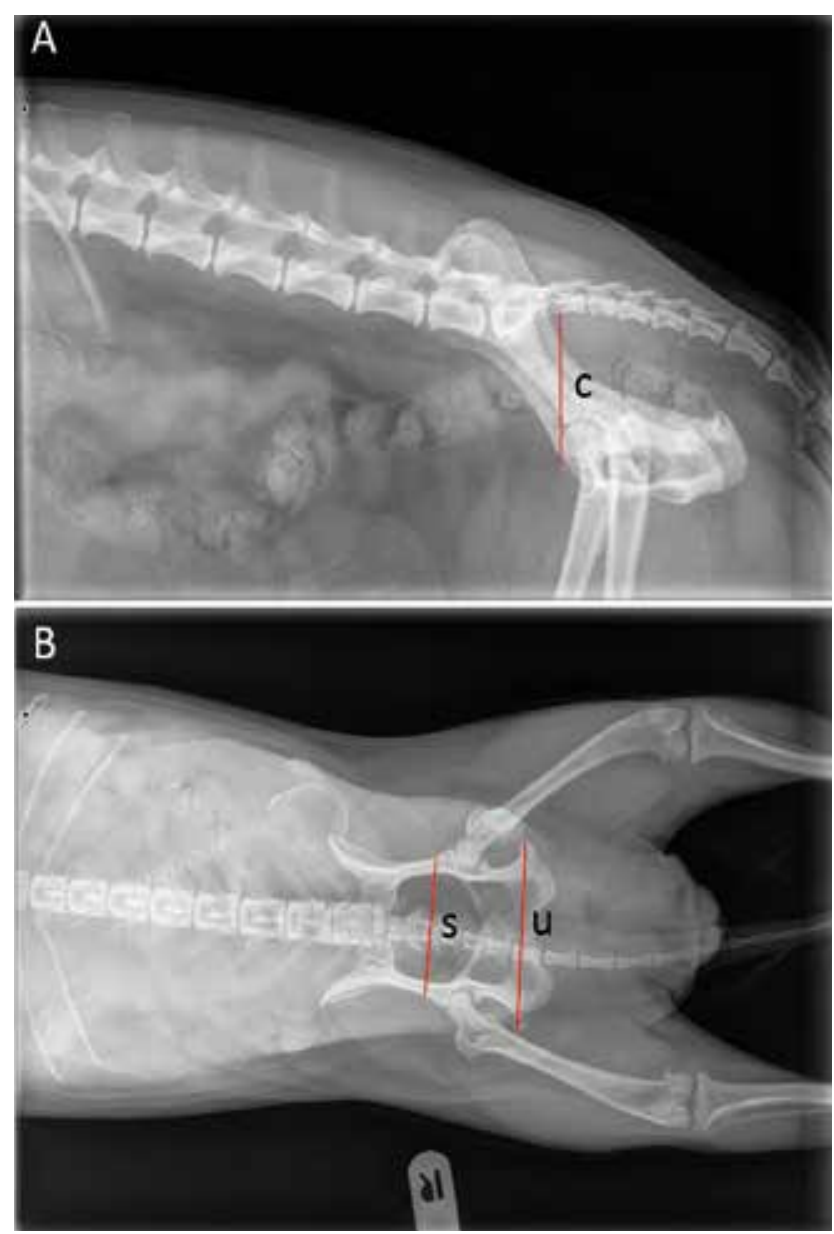

Figuur 2. A. Laterale radiografische opname van het bekken van een risicopatiënt waarop de hoogte (c) van het bekken kan gemeten worden. B. Ventrodorsale radiografische opname van het bekken waarop de breedte van het bekkenkanaal ter hoogte van de iliumvleugels (s) en ter hoogte van het os pubis (u) kunnen gemeten worden. Deze hond heeft een c/sverhouding van 0,93 en een c/u-verhouding van 0,54 , wat predisponeert voor dystocie. Bovendien is er maar één pup aanwezig (Afbeeldingen: dierenarts Dieter Verdonck).
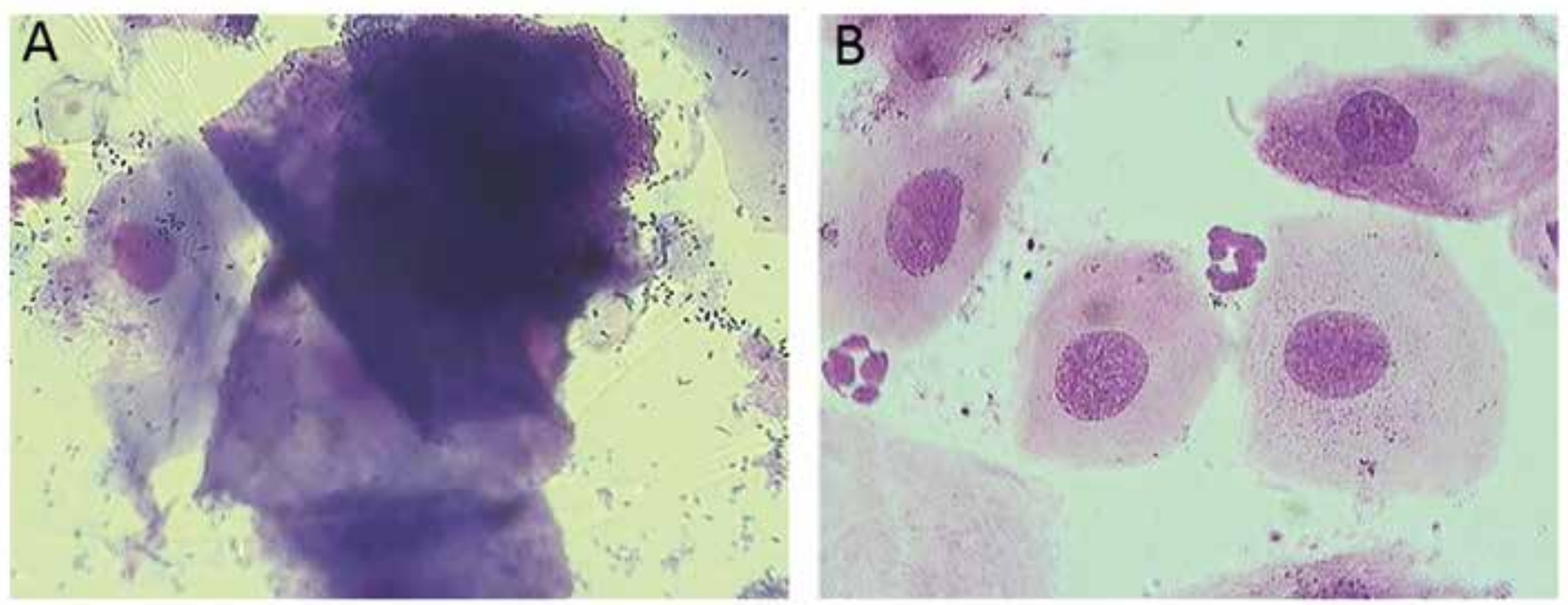

Figuur 3. Vaginale cytologie bij een teef. A. Oestrusbeeld: een schollenbeeld met verhoornde cellen (superficiële cellen en anucleairen) en kiemen. B. Metoestrusbeeld: intermediaire cellen, neutrofielen en kiemen. 
Tabel 1. Voorspelling van partusdatum op \pm 2 dagen (dagen tot partus, DTP) in functie van de meting en de rasgrootte.

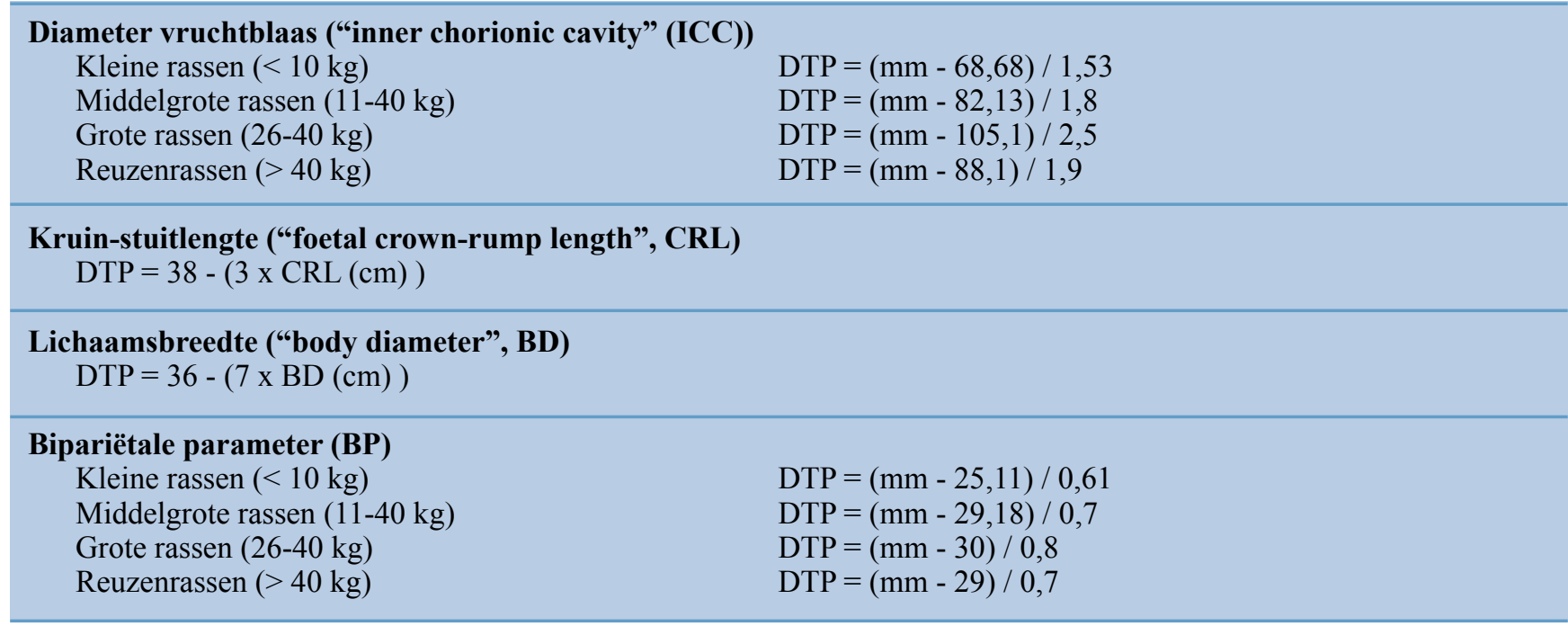

wetende dat de eerste dag van de cytologische metoestrus vijf tot zeven dagen na de ovulatie optreedt (Johnston et al., 2001b). Voor meer informatie omtrent de staalname van een vaginaal uitstrijkje, de verwerking van het staal en interpretatie van de beelden wordt verwezen naar Wydooghe et al. (2013).

\section{Progesteronbepaling}

Bij de hond kan op een indirecte manier het moment waarop de LH-piek en de ovulatie optreden, bepaald worden door de progesteronwaarden in het bloed te meten. Deze beginnen reeds te stijgen vóór de ovulatie, doordat er preovulatoire luteinisatie optreedt. Om dit moment zeker niet te missen, wordt de cyclusopvolging idealiter gestart vijf tot zeven dagen na de start van het bloedverlies. De serumprogesteronconcentraties zijn basaal tot in de late pro-oestrus, daarna begint het progesteron te stijgen. Een progesteronwaarde van 1 tot $3 \mathrm{ng} / \mathrm{ml}$ wijst op het optreden van de LH-piek, die aanleiding geeft tot de ovulatie. Bij honden treedt de ovulatie ongeveer 48 uur na de LH-piek op, het serumprogesteron heeft dan een concentratie van 4 tot $8 \mathrm{ng} / \mathrm{ml}$. Het vaststellen van de ovulatie is het belangrijkste onderdeel van de cyclusopvolging, omdat het optimale moment voor dekking of KI twee tot drie dagen na de ovulatie is, wanneer er rijpe eicellen aanwezig zijn. Anderzijds zijn deze waarden ook belangrijk om de partusdatum te berekenen. Zo vindt de partus plaats $65 \pm 1$ dagen na de LH-piek en $63 \pm 1$ dagen na de ovulatie (Concannon et al., 1983).

\section{Tijdens het tweede en derde trimester van de dracht}

Door middel van echografisch onderzoek kan een tamelijk accurate voorspelling worden gedaan van de partusdatum. Een belangrijk voordeel is dat dit ook kan wanneer het tijdstip van de ovulatie niet bekend is. Met behulp van echografie kan tijdens de dracht een aantal structuren worden opgemeten: de grootte van de vruchtblaas ("inner chorionic cavity", ICC), de lengte van kruin naar stuit ("foetal crown-rump length", CRL) tijdens de eerste helft van de dracht (tussen 19 en 37 dagen na de LH-piek), de lichaamsbreedte ("body diameter", BD) en de afstand tussen

Tabel 2. Het tijdstip van het verschijnen van de verschillende embryonale en foetale structuren op echografisch onderzoek (Naar Lopate, 2012).

\section{Echografisch beeld}

Vruchtblaas

Embryo

Hartslag

Onderscheid hoofd en lichaam

Foetale beweging

Maag

Blaas

Longen

Nieren

Ogen

Darmen
Dagen na LH-piek

23-25

23-25

28

35

35-39

$35-39$

$38-42$

$39-47$

$39-47$

$57-62$

Dagen voor de partus

45

40-42

40-42

37

30

26-32

26-32

23-27

$18-26$

$18-26$

3-8 

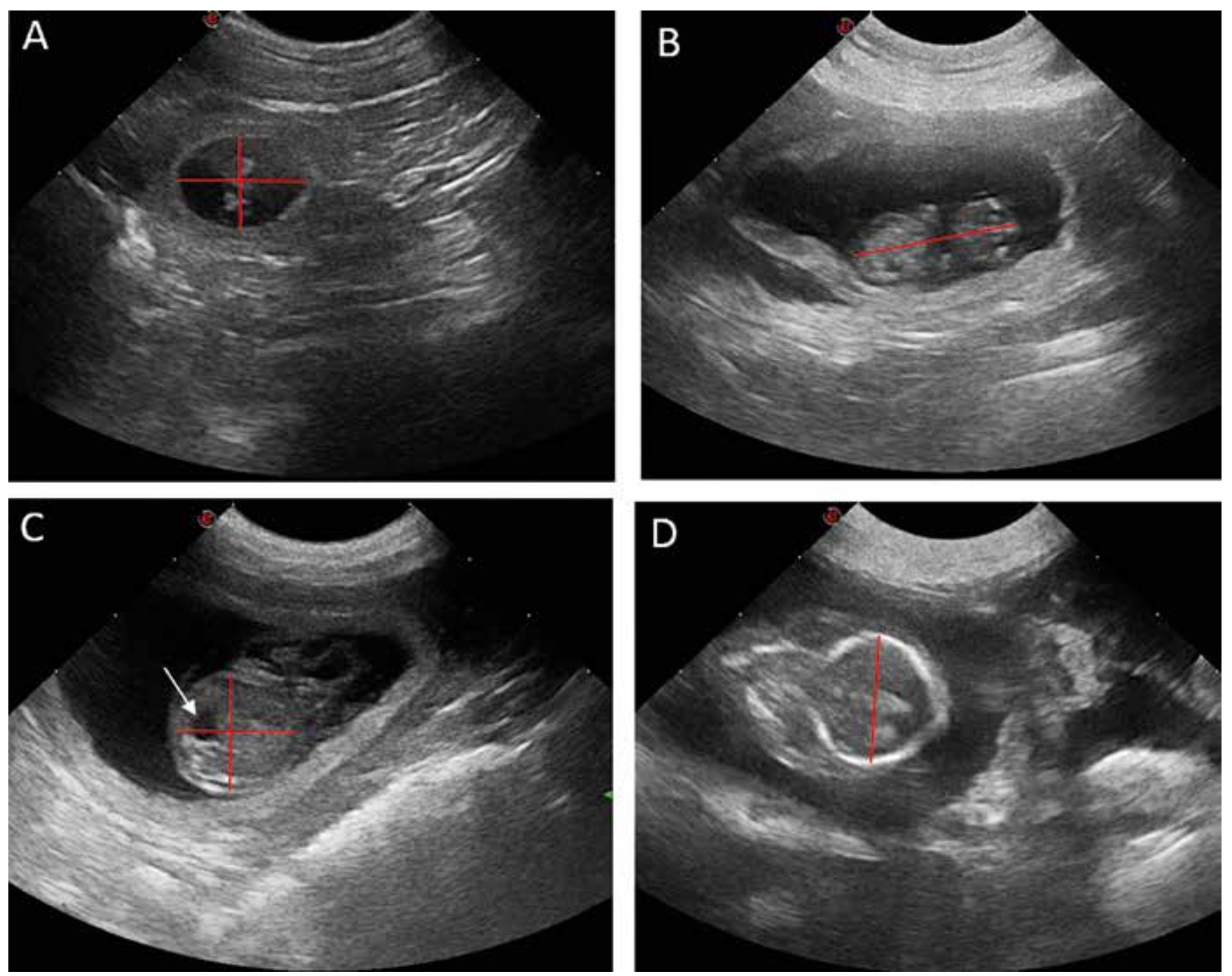

Figuur 4. Het berekenen van de partusdatum met behulp van echografie. A. Meting van de diameter van de vruchtblaas of "inner chorionic cavity" (ICC). B. Meting van de kruin-stuit lengte ("foetal crown-rump lenght", CRL). C. Meting van de lichaamsbreedte ("body diameter", BD) ter hoogte van de maag (witte pijl). D. Meting van de bipariëtale parameter (BP).

de schedelbeenderen (bipariëtale parameter, BP) tijdens de tweede helft van de dracht (England et al., 1990; Luvoni en Grioni, 2000; Luvoni en Beccaglia, 2006; Lopate, 2008; Michel et al., 2011; Beccaglia et al., 2016) (Figuur 4A, 4B, 4C, 4D).

De ICC is de meest gebruikte parameter om de partusdatum te voorspellen tijdens de vroege dracht, terwijl de BP de meest gebruikte parameter is in de tweede helft van de dracht (Luvoni en Beccaglia, 2006). Aan de hand van een formule kan het aantal dagen vooraleer de partus optreedt ("days before parturition", DBP) berekend worden (Tabel 1). Bij honden zijn verschillende formules opgesteld voor kleine en middelgrote rassen (Michel et al., 2011; Beccaglia en Luvoni, 2012) en recent werden de formules ook aangepast voor grote en reuzenrassen (Alonge et al., 2016). De accuraatheid van de formules is onderhevig aan enkele variaties. Zo is de accuraatheid van de BP-waarde beter bij normale nestgroottes en lager bij abnormaal grote of abnormaal kleine nesten. Ook rasverschillen kunnen een rol spelen. De Duitse herder en de bassethound worden gekenmerkt door kortere drachtperioden, andere rassen zoals de westhighlandwhiteterriër eerder door lange drachtperioden (Beccaglia et al., 2016). Voor de Duitse herder werden rasspecifieke formules opgesteld voor de ICC en BP (Groppetti et al., 2015).

Naast het uitvoeren van metingen voor de bepaling van de partusdatum kan tijdens het echografische onderzoek ook gekeken worden naar de foetale ontwikkeling (Tabel 2). Hierbij kan de partusdatum niet precies worden voorspeld maar kan er wel een inschatting worden gemaakt van hoe lang de teef al drachtig is. Een vruchtblaas kan worden opgemerkt vanaf 20 dagen na de LH piek (of 18 dagen na de ovulatie). Op dat moment ziet de vruchtblaas eruit als een anechogene ronde structuur van ongeveer $2 \mathrm{~mm}$ diameter met hyperechogene aflijning. De verdere embryonale ontwikkeling wordt hierna besproken telkens in relatie tot de LH-piek. Daarbij wordt dus een drachtduur van $65 \pm 1$ dagen verwacht. Het embryo is voor het eerst zichtbaar in de vruchtblaas rond dag 23 tot 25 . Op dat moment is ook een hartslag zichtbaar. Vanaf 28 dagen is een duidelijke oriëntatie waarneembaar, 
waarbij het hoofd en de romp van elkaar onderscheiden kunnen worden. De aanzet van de poten en de beweging van de foetus zijn waarneembaar rond dag 35. Mineralisatie van het skelet is echografisch zichtbaar vanaf 33 dagen, waarbij eerst de schedel zichtbaar wordt en vervolgens de wervelkolom, ribben en het appendiculaire skelet. De maag en urineblaas zijn de eerste abdominale organen die zichtbaar worden; dit rond dag 35 tot 39 . De longen worden hyperechogeen ten opzichte van de lever rond dag 38 tot 42 . De nieren en ogen zijn zichtbaar vanaf dag 39 tot 47 (Nyland en Mattoon, 2002). Het laatste orgaan dat wordt aangelegd is de darm. Tijdens de laatste fase van de aanleg van de darmen (dag 57 tot 62) zijn verschillende lagen te herkennen in de darmwand en is er elke drie seconden peristaltiek zichtbaar (Gil et al., 2015).

\section{Bij een nakende partus}

Tijdens de laatste week van de dracht zijn heel wat fysieke veranderingen waarneembaar bij de teef, zoals zwelling van de melkklieren en de aanwezigheid van melk in de tepels. Er treden ook gedragsveranderingen op. Dit zijn evenwel minder betrouwbare kenmerken, niet alleen omdat deze vaak al enkele dagen vóór de geboorte kunnen worden opgemerkt maar ook omdat ze ook bij schijndrachtige dieren kunnen voorkomen (Fontbonne, 2010). Wanneer met zekerheid vastgesteld is dat een hond drachtig is, dan wijzen onrust, nestbouw, graven en krabben heel duidelijk op een naderende partus. Echter, ook hier kunnen sommige dieren deze gedragingen al enkele dagen vóór de partus vertonen. Een heldere, slijmerige uitvloei kan eventueel één of twee dagen voor de partus worden opgemerkt. Wanneer de uitvloei troebel of bloederig wordt, is de ontsluitingsfase begonnen. Sommige honden braken kort vóór of zelfs tijdens de uitdrijving. Opvallend is ook de versnelde ademhaling (Lopate, 2012).

\section{Progesteronconcentratie}

Tijdens de hele dracht is progesteron afkomstig van het corpus luteum verantwoordelijk voor het behoud van de dracht bij honden. Het serumprogesteron daalt abrupt tot $<2 \mathrm{ng} / \mathrm{ml}, 12-40$ uur vóór de geboorte van de eerste pup (Concannon et al., 1978; England en Verstegen, 1996; Veronesi et al., 2002). Het dagelijks opvolgen van de progesteronconcentraties aan het einde van de dracht kan bijgevolg een hulpmiddel zijn om de partus te voorspellen.

Lichaamstemperatuur

Gemiddeld 14 uur na de daling in progesteron (thermogeen hormoon) wordt ook een daling van de lichaamstemperatuur met 0,5 tot $1,5^{\circ} \mathrm{C}$ opgemerkt. Wanneer vanaf de 56ste dag driemaal daags de rectale temperatuur wordt opgemeten en aldus de dagelijkse, fysiologische schommeling gekend is, dan kan op de dag van de partus een daling van de lichaamstemperatuur waargenomen worden. Tussen het moment waarop de laagste temperatuur wordt opgemeten en de uiteindelijke geboorte van de eerste pup kunnen 12 tot 24 uren verlopen; soms echter bedraagt deze periode slechts enkele uren (Lopate, 2012). Deze temperatuurdaling is niet in alle gevallen even duidelijk herkenbaar: Copley (2002) stelde een daling van de lichaamstemperatuur vast bij 81 van 100 teven, terwijl Veronesi et al. (2002) geen temperatuurdaling konden vaststellen bij zeven teven die onderzocht werden (Veronesi et al., 2002).

\section{GEPLANDE KEIZERSNEDE BIJ EEN RISICO- PATIËNT}

Eigenaars van een risicopatiënt kunnen er in samenspraak met de dierenarts voor opteren om de pups te laten geboren worden via een vooraf geplande keizersnede. Bij deze honden wordt het tijdstip van levensvatbaarheid van de foeti bij voorkeur bepaald aan de hand van de progesteronwaarden verkregen tijdens de cyclusopvolging. Zo kan de keizersnede veilig worden uitgevoerd vanaf 62 tot 63 dagen na de LH-piek, of 60 tot 61 dagen na de ovulatie (Concannon, 2000).

Er wordt het beste echter pas gestart met een keizersnede als de progesteronwaarden dalen en de natuurlijke partus op gang komt. Indien de keizersnede uitgevoerd wordt wanneer de progesteronwaarden nog hoog zijn, kunnen er complicaties optreden tijdens de operatie, zoals het moeilijker loskomen van de placenta van de uteruswand (Johnston, 2001a), en kunnen het moederinstinct en de lactatie slecht op gang komen. Daarom wordt geadviseerd om de lichaamstemperatuur of progesterondaling vanaf dag 56 van de dracht op te volgen, zoals eerder besproken, en de keizersnede te starten wanneer een daling van de lichaamstemperatuur of progesteron opgemerkt

Tabel 3. Technieken om verlengde dracht bij de teef vast te stellen (naar Lopate, 2012).

\begin{tabular}{ll}
\hline Techniek & Verlengde dracht \\
\hline Vaginale cytologie & $>60$ dagen na begin metoestrus \\
Progesteronbepaling & $>65$ dagen na ovulatie \\
Progesteronbepaling & $>67$ dagen na LH-piek \\
Echografie & Overschrijden berekende partusdatum met 2 dagen \\
Temperatuurdaling & $>24$ uur na de temperatuurdaling \\
\hline
\end{tabular}


wordt. Echter, bij extreem kleine nesten bestaat er een reëel risico dat de partus niet spontaan op gang komt, waardoor het niet zinvol is om te wachten op een temperatuur- of progesterondaling. Het gevaar bij een dracht van slechts één pup bestaat erin dat er te lang gewacht wordt om een keizersnede uit te voeren. Daarom is het belangrijk om niet langer te wachten dan 67 dagen vanaf de LH-piek of meer dan 65 dagen vanaf de ovulatie om de keizersnede uit te voeren (Lopate, 2012).

\section{KEIZERSNEDE BIJ VERMOEDEN VAN VER- LENGDE DRACHT}

Keizersnede is aangeraden in geval van verlengde dracht, dystocie en/of foetale stress.

Verlengde dracht kan worden ingeschat met de gekende technieken voor het bepalen van de partusdatum (Tabel 3). Een verlengde dracht is een dracht van meer dan 60 dagen gerekend vanaf het begin van de metoestrus. Via progesteronmetingen wordt een verlengde dracht verondersteld bij meer dan 67 dagen vanaf de LH-piek of meer dan 65 dagen vanaf de ovulatie. Op echografisch onderzoek wordt een verlengde dracht vermoed bij het overschrijden van de uitgerekende partusdatum met 2 dagen. Ook wanneer de partus niet aanvat 24 uur na de typische daling van de lichaamstemperatuur wordt gesproken van een verlengde dracht (Lopate, 2012).

Bij honden waarbij enkel de dekdata gekend zijn, bestaat er door de lange fertiele periode een reëel risico dat de teef verkeerdelijk aangeboden wordt met het vermoeden van verlengde dracht. Hierbij kan met behulp van radiografisch onderzoek de levensvatbaarheid van de pups worden ingeschat aan de hand van de mineralisatie van de tanden, die typisch zichtbaar wordt rond dag 61 na de LH-piek (Figuur 5). Ook de mineralisatie van de calcaneus, fibula en de verschillende teenkootjes treedt op rond dag 61 na de LH-piek (Lopate, 2012). Bij beide tijdstippen wordt echter een individuele variatie vastgesteld van 58 tot 63 dagen, wat de accuraatheid van deze methode sterk reduceert. Ook radiografische superpositie bemoeilijkt de interpretatie aanzienlijk. Om deze twee redenen wordt de bepaling van de levensvatbaarheid van pups uitsluitend op basis van radiografische opnamen niet aangeraden (Lopate, 2012).

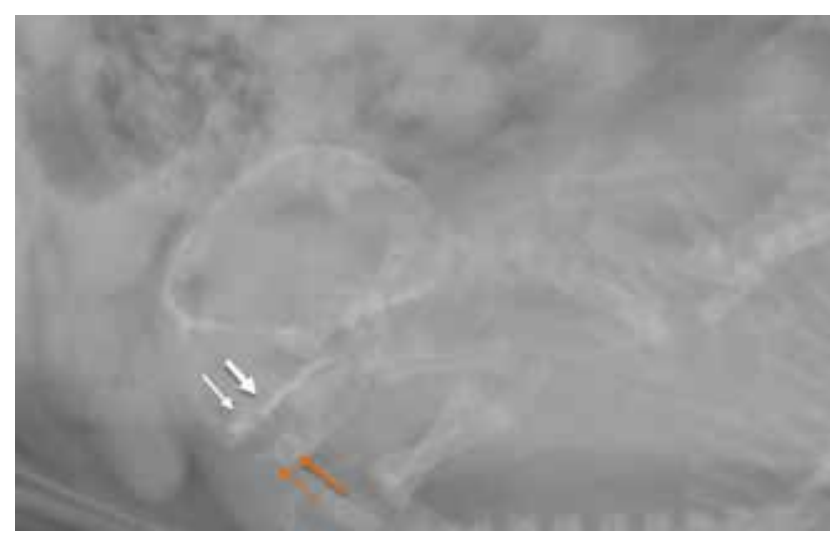

Figuur 5. Beginnende mineralisatie van de tanden in de boven- (witte pijlen) en onderkaak (oranje pijlen) van de foetus 61 dagen na de LH-piek (56 Kv, 12,5 mAs, Sound Eklin Digital X-Ray).

Met behulp van echografie kan de levensvatbaarheid van pups beoordeeld worden door het identificeren van verschillende lagen in hun darmwand en het aantonen van peristaltiek in hun darmen. Echter, het aanwezig zijn van peristaltiek in de darmen wijst op het einde van de organogenese van de pups. Het is echter niet mogelijk om via echografie vast te stellen of de darm ook functioneel (matuur) is (Gil et al. 2015). Daarnaast is het belangrijk om na te gaan of er foetale stress optreedt. Het hartritme van de pups is hiervoor een excellente indicator: het normale hartritme bij de foetus is 2 tot 3 keer het hartritme van de teef (of 220-240 bpm). Een trager hartritme $(<180$ bpm) bij de foetus is een teken van stress die veroorzaakt wordt door hypoxie bij het loslaten van de placenta (Zone en Wanke, 2001). Er moet opgemerkt worden dat uteriene contracties een tijdelijke daling in de hartslag kunnen veroorzaken, die binnen 1 à 2 minuten terug dient genormaliseerd te zijn. Indien de hartslag laag blijft, is dat een indicatie om over te gaan tot een spoedkeizersnede.

\section{KEIZERSNEDE BIJ VERMOEDEN VAN DYS- TOCIE}

Dystocie kan worden vermoed wanneer de teef gedurende 30 minuten krachtige en frequente persbewegingen makkt of gedurende 2 uur zwakke persbewegingen maakt zonder vordering van een pup in het

Tabel 4. Tekenen van dystocie bij de hond (uit: Johnston et al., 2001a).

Een pup zit vast in het geboortekanaal

Meer dan 12 uur na de temperatuurdaling zonder geboorte van een pup

Groene uitvloei vóór de geboorte van de eerste pup

Verlies van vruchtwater maar geen vordering bij de partus 2 tot 4 uur nadien

Dertig minuten krachtig en frequent persen zonder vordering van de pup in het bekkenkanaal

Twee uur zwakke persbewegingen zonder vordering van de pup in het bekkenkanaal

Meer dan 4 uur tussen de geboorte van twee pups

Ziekteverschijnselen bij de teef: bvb. eclampsia 
bekkenkanaal. Er is tevens sprake van dystocie wanneer er meer dan 4 uur tussen de geboorte van twee pups zit of wanneer er een groene tot zwarte vaginale uitvloei aanwezig is die kan wijzen op loslating van de placenta of op dode foeti (Johnston et al., 2001a) (Tabel 4). Dystocie kan ook worden vermoed wanneer de temperatuurdaling meer dan 24 uur eerder werd vastgesteld, wanneer 2 tot 4 uur voordien het verlies van vruchtwater werd opgemerkt maar nog geen pups geboren zijn. Daarnaast is het ook belangrijk om snel in te grijpen wanneer de teef ziekteverschijnselen als lethargie, shocksymptomen, sterke dehydratatie of eclampsia vertoont.

Wanneer er nog geen pups geboren zijn, is het net als bij het vermoeden van een verlengde dracht belangrijk om de levensvatbaarheid van de pups na te gaan met radio- en/of echografie. Daarnaast kan ook het aan- of afwezig zijn van foetale stress geëvalueerd worden. Contra-indicaties voor het uitvoeren van een keizersnede zijn een geïnfecteerde uterusinhoud, de aanwezigheid van emfysemateuze foeti, ernstige verwondingen van de geboorteweg of een slechte algemene toestand van de moeder. Bij deze laatste wordt een stabiliserende behandeling opgestart vooraleer er al dan niet tot een keizersnede wordt overgegaan (Johnston et al., 2001a).

\section{CONCLUSIE}

Om de kans op overleving van pups te maximaliseren is het belangrijk dat bij de teef een keizersnede wordt uitgevoerd op het optimale tijdstip. Dit moment is afhankelijk van de berekende partusdatum en van het al of niet aanwezig zijn van verlengde dracht of dystocie. Bij de hond kan de partusdatum berekend worden door het begin van de metoestrus te bepalen via vaginale cytologie of door embryonale en foetale structuren te meten via echografie. Dit laatste kan tevens gebeuren indien de cyclus van de teef niet werd opgevolgd. De meest accurate methode om het tijdstip van de partus te bepalen is echter door middel van cyclusopvolging met progesteronmetingen. Bij het vermoeden van verlengde dracht en/of dystocie dient de keizersnede te worden aangevat. Op het moment van de keizersnede dient de levensvatbaarheid van de pups ingeschat te worden aan de hand van echografie (verschillende lagen in de darmwand, aanwezigheid van darmperistaltiek) en/of radiografie (mineralisatie tanden). Foetale stress kan ingeschat worden door het hartritme echografisch te evalueren (moet hoger zijn dan $180 \mathrm{bmp})$.

\section{REFERENTIES}

Alonge S., Beccaglia M., Melandri M., Luvoni G.C. (2016). Prediction of whelping date in large and giant canine breeds by ultrasonography foetal biometry. Journal of Small Animal Practice 57, 479-483.
Beccaglia M., Alonge S., Trovo C., Luvoni G.C. (2016). Determination of gestational time and prediction of parturition in dogs and cats: an update. Reproduction of Domestic Animals 51 Suppl 1, 12-17.

Beccaglia M., Luvoni G.C. (2012). Prediction of parturition in dogs and cats: accuracy at different gestational ages. Reproduction of Domestic Animals 47, 194-196.

Bergstrom A., Nodtvedt A., Lagerstedt A.S., Egenvall A. (2006). Incidence and breed predilection for dystocia and risk factors for cesarean section in a Swedish population of insured dogs. Veterinary Surgery 35, 786-791.

Concannon P. (2000). Canine pregnancy: predicting parturition and timing events of gestation. Recent Advances in Small Animal Reproduction. International Veterinary Information Services (www. ivis. org).

Concannon P., Butler W., Hansel W., Knight P., Hamilton J. (1978). Parturition and lactation in the bitch: serum progesterone, cortisol and prolactin. Biology of Reproduction 19, 1113-1118.

Concannon P., Whaley S., Lein D., Wissler R. (1983). Canine gestation length: variation related to time of mating and fertile life of sperm. American Journal of Veterinary Research 44, 1819-1821.

Copley K. (2002). Comparison of traditional methods for evaluating parturition in the bitch versus using external fetal and uterine monitoring. In: Proceedings of the Society of Theriogenology Annual Conference. Colorado Springs, CO. pg 375-382

Davidson A. (2010). Problems during and after parturition. BSVA Manual of Canine and Feline Reproduction and Neonatology. Second edition. Gloucester: BSVA, 121134.

De Cramer K.G.M., Nothling J.O. (2017). The precision of peri-oestrous predictors of the date of onset of parturition in the bitch. Theriogenology 96, 153-157.

De Kruif A. (2012). Voortplanting van de huisdieren. Cursus faculteit diergeneeskunde, Gent.

Eneroth A., Linde-Forsberg C., Uhlhorn M., Hall M. (1999). Radiographic pelvimetry for assessment of dystocia in bitches: a clinical study in two terrier breeds. Journal of Small Animal Practice 40, 257-264.

England G., Allen W.E., Porter D. (1990). Studies on canine pregnancy using B-mode ultrasound: Development of the conceptus and determination of gestational age. Journal of Small Animal Practice 31, 324-329.

England G., Verstegen J. (1996). Prediction of parturition in the bitch using semi-quantitative ELISA measurement of plasma progesterone concentration. Veterinary Record $139,496-496$.

Fontbonne A. (2010). Clinical approach to conditions of the non-pregnant or neutered bitch. BSAVA Manual of Canine and Feline Reproduction and Neonatology. Second edition, British Small Animal Veterinary Association, Quedgeley, 166-184.

Gavrilovic B.B., Andersson K., Forsberg C.L. (2008). Reproductive patterns in the domestic dog - A retrospective study of the Drever breed. Theriogenology 70, 783-794.

Gil E.M., Garcia D.A., Froes T.R. (2015). In utero development of the fetal intestine: Sonographic evaluation and correlation with gestational age and fetal maturity in dogs. Theriogenology 84, 681-686.

Groppetti D., Vegetti F., Bronzo V., Pecile A. (2015). Breed-specific fetal biometry and factors affecting the prediction of whelping date in the German shepherd dog. Animal Reproduction Science 152, 117-122. 
Johnston S., Kustritz M.R., Olson P. (2001a). Canine parturition-eutocia and dystocia. In: Johnston S., Root Kustritz M., Olson P. (editors). Canine and Feline Theriogenology. WB Saunders, Philadelphia, 105-128.

Johnston S., Root Kustritz M., Olson P. (2001b). The canine estrous cycle. In: Johnston S., Root Kustritz M., Olson P. (editors). Canine and Feline Theriogenology, 16-31.

Levy X., Fontaine E., Segalini V., Fontbonne A. (2009). Elective caesarean operation in the bitch using aglepristone before the pre-partum decline in peripheral progesterone concentration. Reproduction of Domestic Animals 44, 182-184.

Linde-Forsberg C. 2005. Abnormalities in pregnancy, parturition and the periparturient period.In: S. Ettinger, E. Feldman (editors). Textbook of Veterinary Obstetrics. WK Saunders Co., London, pg 1655-1667.

Lopate C. (2008). Estimation of gestational age and assessment of canine fetal maturation using radiology and ultrasonography: a review. Theriogenology 70, 397-402.

Lopate C. (2012). Management of Pregnant and Neonatal Dogs, Cats, and Exotic Pets. John Wiley \& Sons.

Luvoni G., Grioni A. (2000). Determination of gestational age in medium and small size bitches using ultrasonographic fetal measurements. Journal of Small Animal Practice 41, 292-294.

Luvoni G.C., Beccaglia M. (2006). The prediction of parturition date in canine pregnancy. Reproduction of Domestic Animals 41, 27-32.
Mattoon J.S., Nyland T.G. (2002). Ovaries and Uterus. In: Mattoon J.S., Nyland T.G. (editors). Small Animal Diagnostic Ultrasound. Elsevier Health Sciences, 634-654.

Michel E., Spörri M., Ohlerth S., Reichler I. (2011). Prediction of parturition date in the bitch and queen. Reproduction in Domestic Animals 46, 926-932.

Moon, P. F., Erb, H. N., Ludders, J. W., Gleed, R. D., Pascoe, P. J. (2000). Perioperative risk factors for puppies delivered by cesarean section in the United States and Canada. Journal of the American Animal Hospital Association 36(4), 359-368.

Smith F.O. (2007). Challenges in small animal parturition -Timing elective and emergency cesarian sections. Theriogenology 68, 348-353.

Veronesi M., Battocchio M., Marinelli L., Faustini M., Kindahl H., Cairoli F. (2002). Correlations among body temperature, plasma progesterone, cortisol and prostaglandin F $2 \alpha$ of the periparturient bitch. Transboundary and Emerging Diseases 49, 264-268.

Wydooghe E., Van Soom A., Rijsselaere T. (2013). Vaginale cytologie bij de teef: een miskende techniek? Vlaams Diergeneeskundig Tijdschrift 82, 363-369.

Zone M., Wanke M. (2001). Diagnosis of canine fetal health by ultrasonography. Journal of Reproduction and Fertility 57, 215-219.

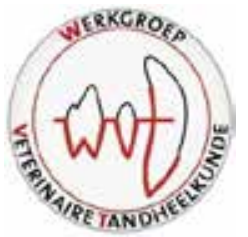

\title{
Practical Feline Veterinary Dentistry
}

\author{
Zaterdag 27 januari 2018, \\ Theater \& Congrescentrum Orpheus Apeldoorn \\ Nederland
}

De Werkgroep Veterinaire Tandheelkunde en Virbac presenteren op zaterdag 27 januari wederom een inspirerend programma voor de tandheelkundig geïnteresseerde dierenarts en paraveteriniar!

Het Tandheelkundig Symposium 2018 heeft als thema 'Tandheelkunde bij de kat' en biedt een divers en inspirerend programma. Tijdens deze inspirerende dag zullen vele dimensies van het vakgebied tandheelkunde aan bod komen. Door het uitgebreide programma aan spraakmakende, praktische en informatieve lezingen met o.a. gerenommeerde gastsprekers zoals dr. Jerzy Pawel Gawor, Diplomate van de European Veterinairy Dental College en de American Veterinary Dental College. Daarnaast zal onderzoekswetenschapper dr. Corrin Wallis het belang van de flora in de mondholte van de kat presenteren en zal gedragswetenschapper dr. Tammie King ons op praktische wijze inzicht geven in kattengedrag.

De fantastisch sfeervolle locatie, makkelijk bereikbaar en met een uitstekende catering, zal plaats bieden aan een uitgebreide up-to-date infomarkt van de tandheelkundige toeleveranciers. Als u op zoek ben naar een goede en praktische basis voor de tandheelkunde bij de kat, dan zijn de lezingen onmisbaar!

Voor meer informatie en een uitgebreid programmaoverzicht: https://virbac.nl/Actueel 